\title{
Perbedaan Pengaruh Latihan Konsentrasi Dan Latihan Koordinasi Terhadap Peningkatan Kemampuan Shooting Game Atlet Petanque Undikma
}

\author{
${ }^{\mathbf{1}}$ Muhammad Ridwan Lubis, ${ }^{2}$ Andi Gilang Permadi \\ ${ }^{12}$ Program Studi Pendidikan Olahraga dan Kesehatan, Fakultas Fakultas Ilmu Keolahragaan dan \\ Kesehatan Masyarakat, Universitas Pendidikan Mandalika \\ Email: mridwanlubis@ikipmataram.ac.id
}

\begin{abstract}
This research is motivated by the inconsistency of the shooting ability of athletes in shooting games in Petanque sports, both at the regional and national levels. This study aims to determine the effect of concentration training and coordination training on the improvement of the shooting game ability of Undikma petanque athletes. This study used an experimental method with the design of "two group pretest posttest design". The research instrument used was a shooting ability test with shooting stations 1, 2, 3, 4, and 5 with a distance of 6 meters, 7 meters, 8 meters, and 9 meters. The sample in this study were 14 Undikma Petanque athletes. Sampling using purposive sampling technique. Based on the results of the t-test analysis showed the same significant results between concentration training and coordination training. However, the result of the concentration exercise was better than the coordination exercise. It was seen that the average value of shooting using the pretest result of concentration training was 4.71 which increased by 13.00 . The amount of increase was 8.28. The coordination exercise, which was originally the pretest average result of 3.42 increased to 10.00 . The amount of increase was 6.57. The difference in the average result of shooting game improvement with concentration training and coordination training is 1.71 .
\end{abstract}

Keywords: Konsentrasi, Koordinasi, Shooting.

Abstrak. Penelitian ini dilatar belakangi oleh belum konsistennya kemampuan shooting atlet dalam pertandingan shooting game pada permaianan cabang olahraga petanque baik itu di level ragional maupun level nasional. Penelitian ini bertujuan untuk mengetahui pengaruh latihan konsentrasi dan latihan koordinasi terhadap peningkatan kemampuan shooting game atlet petanque Undikma. Penelitian ini menggunakan metode eksperimen dengan desain "two group pretest posttest design". Instrument penelitian yang digunakan adalah tes kemampuan shooting dengan shooting station 1, 2, 3, 4, dan 5 dengan jarak 6 meter, 7 meter, 8 meter, dan 9 meter. Sampel dalam penelitian ini adalah atlet petanque Undikma yang berjumlah 14 orang. Pengambilan sample menggunakan teknik purposive sampling. Berdasarkan hasil analisis uji-t menunjukkan hasil yang sama signifikan antara latihan konsentrasi dan latihan koordinasi. Namun latihan konsentrasi hasilnya lebih baik daripada latihan koordinasi terlihat dengan nilai rata-rata shooting menggunakan latihan konsentrasi hasil pretest 4,71 meningkat sebesar 13,00. Jumlah peningkatan sebesar 8,28. Latihan koordinasi yang semula hasil rata-rata pretest 3,42 meningkat menjadi 10,00. Jumlah peningkatan sebesar 6,57. Selisih rata-rata penigkatan hasil shooting game dengan latihan konsentrasi, dan latihan koordinasi adalah 1,71.

Kata Kunci: Konsentrasi, Koordinasi, Shooting

\section{PENDAHULUAN}

Petanque adalah bentuk permainan boules yang tujuannya melempar bola besi (bosi) sedekat mungkin dengan bola kayu yang disebut jack dan kedua kaki harus berada di lingkaran kecil, ada juga kompetisi khusus untuk shooting (Lubis, 2019: 287). Ada 2 jenis lemparan dalam olahraga petanque yaitu pointing dan shooting. Pointing adalah jenis lemparan untuk mendekati jack lebih dekat dari bosi lawan yang merupakan awal dari strategi permainan yang akan dilakukan pada pertadingan petanque. pointing pada pertandingan petanque merupakan strategi untuk bertahan. Biasanya atlet pemula yang sering melakukan strategi ini. Shooting adalah jenis lemparan untuk mengusir bosi lawan dari jack. Shooting merupakan bagian terpenting pada permaianan petanque. Apabila dalam satu tim kemampuan shooting lemah, maka tim tersebut akan kesulitan dalam menyerang bosi lawan. Objek penelitian yang menjadi fokus penelitian ini adalah shooting.

Lubis (2019: 290) shooting adalah jenis lemparan untuk mengusir bosi lawan dari boka 
target (jack). Shooting tidak perlu deskripsi panjang: mengarahkan pada bola target (fokus pada bola target, bukan jebakan bola) dan mencoba untuk mendaratkan bola di atas bola target dan mendorongnya keluar lapangan. Shooting utama disebut "Carreau" dimana subjek menembak bola posisi pada penuh sehingga bola target dihapus dan bola shooter dan mengambil tempatnya dan dengan mempertahankan titik atau masih berada di dekat posisi awal bola target, Lubis (2019: 300). Dengan demikian tingkat kesulitan dalam melakukan shooting lebih tinggi jika dibandingkan dengan pointing. Irmansyah et al. (2019: 163) mengemukakan bahwa, ada empat aspek latihan yang perlu diperhatikan dan dilatih secara seksama, yaitu latihan fisik, latihan teknik, latihan taktik, dan latihan mental (psikologis) merupakan bagian yang tak terpisahkan dari aspek latihan, sehingga harus diprioritaskan sebagaimana aspek-aspek latihan yang lain.

Penguasaan teknik dasar itu tentunya sangat memerlukan peran latihan mental dan kondisi fisik yang baik, karena tanpa itu semua seorang atletk tidak akan mencapai prestasi yang diharapkan (Lengkanan, 2013).

Berdasarkan hasil pengamatan yang dilakukan peneliti disesi latihan klub petanque Undikma, sebahagian besar para atlet belum dapat mengatur tenaga dengan baik ketika melakukan shooting, kurang dapat melakukan koordinasi yang baik antara pandangan, ayunan lengan dan posisi tubuh ketika melakukan lemparan.

Hubungan dengan penelitian ini adalah peneliti ingin memberikan sebuah metode latihan mental/psikologis dan latihan fisik untuk atlet petanque Undikma agar mampu meningkatkan kemampuan shooting, model latihan mental berupa latihan konsentrasi dan latihan fisik berupa latihan koordinasi.

Loehr (1986: 80) atlet dikatakan memiliki konsentrasi apabila atlet memiliki fokus yang benar ketika apa yang sedang kita kerjakan selaras dengan apa yang sedang kita pikirkan. Selanjutnya Loehr (1986: 81) menyatakan atlet yang memiliki konsentrasi akan mampu mengendalikan aliran energi positif dan energi negatif, seperti atlet tidak mampu mengelola berbagai tekanan yang menimpa dirinya berarti atlet tidak memiliki konsentrasi yang baik. Bahwa atlet yang memiliki energi negatif tinggi akan hilang konsentrasi, pandangan tidak fokus, perhatiannya sangat sempit. Dampaknya terhadap atlet yaitu tidak menyenangkan. Atlet yang memiliki energi negatif yang rendah akan hilang konsentrasi, begitupun atlet yang memiliki energi campuran antara positif dan negatif, akan berdampak pada keadaan yang tidak menyenangkan. Selanjutnya bagi atlet yang memiliki energi positif rendah juga akan kurang konsentrasi, mudah bingung, bimbang, kacau, dan perhatiannya menjadi terlalu luas. Sedangkan bagi atlet yang memiliki energi positif yang tinggi akan memiliki konsentrasi yang baik dan berhasil dalam menampilkan tugasnya sehingga atlet merasa senang.

Latihan koordinasi tidak kalah pentingnya untuk diberikan pelatihan khusus. Koordinasi yang harus dimiliki oleh seorang atlet petanque cenderung mengarah ke koordinasi mata-tangan. Koorndinasi mata-tangan adalah kemampuan untuk melakukan aktivitas yang membutuhkan penggunaan tangan dan mata secara simultan, sperti aktivitas yang menggunakan informasi yang diliha mata kita (persepsi visual-spasial) untuk memandu tangan kita untuk melakukan gerakan (Curran, 2018). Meskipun atlet memiliki kekuatan yang baik namun apabila pada saat melempar bosi mereka tidak bisa mengarahkannya ke bosi target dengan tepat dan akurat dengan pandangan dan posisi tubuh yang benar maka tidak akan menghasilkan lemparan shooting yang baik.

Berdasarkan hal tersebut, maka penelitian ini bertujuan untuk mengetahui perbedaan pengaruh latihan konsentrasi dan latihan koordinasi untuk meningkatkan kemampuan shooting pada atlet petanque Undikma.

\section{METODE}

Penelitian ini adalah eksperimen semu, artinya karena sampel tidak dikarantina atau tidak di asramakan. Penelitian eksperimen bertujuan untuk menyelidiki kemungkinan saling hubungan sebab akibat dengan cara mengenakan kepada satu atau lebih kelompok eksperimental, satu kelompok atau lebih kelompok yang diberikan dan membandingkan 
hasilnya dengan satu atau lebih kelompok kontrol yang tidak dikenai perlakuan (Sugiyono, 2007: 51). Desain penelitian yang digunakan adalah "Two Group Pretest Posttest Design", yaitu desain penelitian yang terdapat pretest sebelum diberikan perlakuan dan posttest setelah diberikan perlakuan. Dengan demikian dapat diketahui lebih akurat, karena dapat membandingkan dengan diadakan sebelum diberi perlakuan (Sugiyono, 2007: 64). Dengan latihan yang diberikan tersebut, akan terlihat hubungan sebab akibat sebagai pengaruh dari pelaksanaan latihan. Dalam penelitian ini penulis ingin mengetahui perbedaan hasilnya yang lebih baik antara latihan konsentrasi dan latihan koordinasi terhadap peningkatan kemampuan shooting game atlet petanque Undikma. Kemudian dari hasil tersebut pelatih atau atlet bisa menggunakan bahkan mengembangkan model latihan seperti yang digunakan oleh penulis berikan kepada subjek penelitian untuk variasi dalam program latihannya.

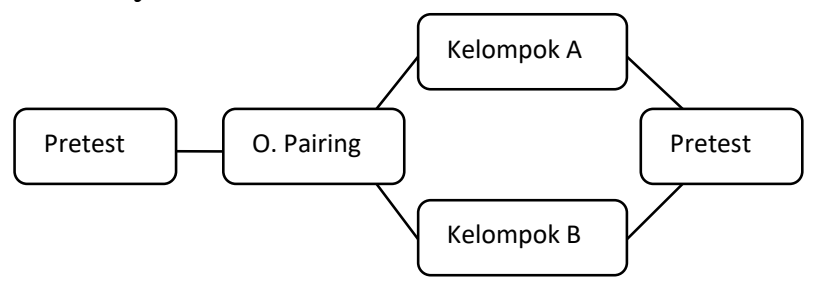

Gambar 1. Alur Penelitian

Menurut Suharsimi (2006: 101) populasi adalah keseluruhan subjek penelitian. Populasi dalam penelitian ini adalah atlet petanque Undima yang berjumlah 24 atlet. Sampel adalah sebagian atau wakil populasi yang diteliti (Suharsimi Arikunto, 2006: 117). Teknik sampel dalam penelitian ini adalah purposive sampling, teknik ini didasarkan atas tujuan tertentu. Adapun syarat-syarat yang harus dipenuhi dalam pengambilan sampel ini, yaitu;(1) atlet petanque Undikma, (2) atlet yang pernah mengikuti kejuaraan regional ataupun nasional, (3) bersedia mengikuti latihan selama penelitian berlangsung. Berdasarkan kriteria tersebut yang memenuhi adalah berjumlah 14 atlet.

Seluruh sampel tersebut dikenai pretest untuk menentukan kelompok treatment, dirangking nilai pretest-nya, kemudian dipasangkan (matced) dengan pola A-B dalam dua kelompok dengan anggota masing-masing 7 atlet. Sampel dibagi menjadi dua kelompok, Kelompok I diberi perlakuan latihan konsentrasi dan Kelompok II diberi perlakuan latihan koordinasi selama 6 minggu $16 \quad$ kali pertemuan kemudian dilakukan posttest sama seperti pretest, yaitu tes shooting game. Adapun prosedur pembagian kelompok A dan kelompok B adalah dengan mengunakan ordinal pairing. Langkah pertama adalah melakukan pretest pada pertemuan pertama yaitu melakukan pretest, lalu kemudian hasil tersebut diranking dari yang tertinggi sampai terendah. Hasil ranking pretest tersebut dibuat ordinal pairing berdasarkan ranking yang diperoleh atlet tersebut.

Sebelum dilakukan pengujian hipotesis, maka perlu dilakukan uji prasyarat. Pengujian data hasil pengukuran yang berhubungan dengan hasil penelitian bertujuan untuk membantu analisis agar menjadi lebih baik. Untuk itu dalam penelitian ini akan di uji normalitas dan uji homogenitas data. Uji statistik pada penelitian ini termasuk dalam statistik parametrik. Statistik paramatrik adalah uji statistik yang memerlukan uji prasyarat, adapun uji prasayarat yang digunakan dalam penelitian ini, yaitu: Uji normalitas tidak lain sebenarnya adalah mengadakan pengujian terhadap normal tidaknya sebaran data yang akan dianalisis. Pengujian dilakukan tergantung variabel yang akan diolah. Pengujian normalitas sebaran data menggunakan Kolmogorov-Smirnov Test dengan bantuan SPSS. Metode Kolmogorov Smirnov, kriteria pengujian adalah sebagai berikut: Jika signifikansi di bawah 0.05 berarti data yang akan diuji mempunyai perbedaan yang signifikan dengan data normal baku, berarti data tersebut tidak normal. Jika signifikansi di atas 0.05 maka berarti tidak terdapat perbedaan yang signifikan antara data yang akan diuji dengan data normal baku, berarti data tersebut normal. Di samping pengujian terhadap penyebaran nilai yang akan dianalisis, perlu uji homogenitas agar yakin bahwa kelompok-kelompok yang membentuk sampel berasal dari populasi yang homogen. Uji homogenitas menggunakan uji $\mathrm{F}$ dari data pretest pada kedua kelompok dengan menggunakan bantuan program SPSS.

Pengujian hipotesis menggunakan uji-t yaitu dengan membandingkan mean antara kelompok 1 dan kelompok 2. Apabila nilai Sig. Lebih dari 0,05, maka hasilnya tidak signifikan, jika nilai Sig. Kurang dari dari 0,05 , maka hasilnya signifikan.

\section{HASIL DAN PEMBAHASAN}

Dari hasil analisis data penelitian kemampuan shooting pretest dan posttest atlet petanque Undikma yang dilakukan dengan latihan konsentrasi, maka dapat di deskripsikan dalam bentuk table sebagai berikut: 
Tabel 1. Latihan Konsentrasi

\begin{tabular}{|c|l|c|c|c|}
\hline No & Nama & Pretest & Posttest & Peningk \\
\hline 1 & Irpan & 14 & 16 & 2 \\
\hline 2 & Lina & 7 & 10 & 3 \\
\hline 3 & Atun & 6 & 11 & 5 \\
\hline 4 & Evi & 3 & 12 & 9 \\
\hline 5 & Zakiya & 3 & 11 & 8 \\
\hline 6 & Irvan & 0 & 14 & 14 \\
\hline 7 & Dian & 0 & 17 & 17 \\
\hline \multicolumn{2}{|c|}{ Jumlah } & $\mathbf{3 3}$ & $\mathbf{9 1}$ & $\mathbf{5 8}$ \\
\hline
\end{tabular}

Tabel 2. Deskripsi Statistik Kemampuan Shooting Game

\begin{tabular}{|l|c|c|}
\hline \multicolumn{1}{|c|}{ Statistik } & Pretest & Posttest \\
\hline Mean & 4,7143 & 13.0000 \\
\hline Median & 3 & 12 \\
\hline Mode & 0 & 11 \\
\hline Std.Deviation & 4,8892 & 2,7080 \\
\hline Minimum & 0 & 10 \\
\hline Maximum & 14 & 17 \\
\hline Sum & 33 & 91 \\
\hline
\end{tabular}

Dari data di atas dapat dideskripsikan bahwa kemampuan shooting atlet petanque Undikma pada saat dilakukan pengambilan data pretest yaitu dengan rata-rata sebesar 4,7143 nilai tengah 3 , nilai yang sering muncul 0 dan simpangan baku 4,8892. Sedangkan skor tertinggi sebesar 14 dan skor terendah sebesar 0 . Kemampuan shooting atlet petanque Undikma pada saat dilakukan pengambilan data posttest yaitu dengan nilai rata-rata sebesar 13,0000, nilai tengah 12 , nilai yang sering muncul 11, dan simpangan baku 2,7080. Sedangkan skor tertinggi sebesar 17 dan skor terendah sebesar 10. Hasil tersebut sudah terlihat adanya peningkatan kemampuan shooting atlet.

Dari hasil analisis data penelitian kemampuan shooting pretest dan posttest atlet petanque Undikma yang dilakukan dengan latihan koordinasi, maka dapat dideskripsikan dalam bentuk tabel sebagai berikut:

Tabel 3. Latihan Koordinasi

\begin{tabular}{|c|l|c|c|c|}
\hline No & Nama & Pretest & Posttest & Peningk \\
\hline 1 & Rian & 8 & 19 & 11 \\
\hline 2 & Putra & 7 & 9 & 2 \\
\hline 3 & kire & 6 & 9 & 3 \\
\hline 4 & Dedi & 3 & 10 & 7 \\
\hline 5 & Fahri & 0 & 11 & 11 \\
\hline 6 & Rista & 0 & 5 & 5 \\
\hline
\end{tabular}

\begin{tabular}{|c|c|c|c|c|}
\hline 7 & Gean & 0 & 7 & 7 \\
\hline \multicolumn{2}{|c|}{ Jumlah } & $\mathbf{2 4}$ & $\mathbf{7 0}$ & $\mathbf{4 6}$ \\
\hline
\end{tabular}

Tabel 4. Deskripsi Statistik Kemampuan Shooting Game

\begin{tabular}{|l|c|c|}
\hline \multicolumn{1}{|c|}{ Statistik } & Pretest & Posttest \\
\hline Mean & 3,4286 & 10,0000 \\
\hline Median & 3 & 9 \\
\hline Mode & 0 & 9 \\
\hline Std.Deviation & 3,5523 & 4,4347 \\
\hline Minimum & 0 & 5 \\
\hline Maximum & 8 & 19 \\
\hline Sum & 24 & 70 \\
\hline
\end{tabular}

Dari data di atas dapat dideskripsikan bahwa kemampuan shooting atlet petanque Undikma pretest dengan nilai rata-rata sebesar 3,4286 , nilai tengah 3 , nilai yang sering muncul 0 dan simpangan baku 3,5523. Sedangkan skor tertinggi sebesar 8 dan skor terendah sebesar 0 . Kemampuan shooting atlet petanque Undikma posttest dengan rata-rata sebesar 10,0000, nilai tengah 9, nilai yang sering muncul 9, dan simpangan baku 4,4347. Sedangkan skor tertinggi sebesar 19 dan skor terendah 5 .

Sebelum dilakukan analisis statistik, terlebih dahulu dilakukan uji asumsi atau uji prasyarat analsisi yang meliputi uji normalitas dan uji homogenitas. Pengujian normalitas menggunakan uji kolmogorov smirnov. Dalam uji ini akan menguji hipotesis sampel dengan membandingkan harga Asymp. Sig. dengan 0,05. Criteria menerima hipotesis apabila Asymp. Sig. lebih besar dari 0.05 , apabila tidak memenuhi criteria tersebut maka hipotesis tidak normal/ditolak.

Tabel 5. Hasil Perhitungan Uji Normalitas

\begin{tabular}{|c|l|c|c|}
\hline No & Variabel & $\begin{array}{c}\text { Asymp. } \\
\text { Sig }\end{array}$ & Kesimpulan \\
\hline 1 & $\begin{array}{l}\text { Latihan } \\
\text { konsentrasi } \\
\text { pretest }\end{array}$ & 0,200 & Normal \\
\hline 2 & $\begin{array}{l}\text { Latihan } \\
\text { konsentrasi } \\
\text { posttest }\end{array}$ & 0,200 & Normal \\
\hline 3 & $\begin{array}{l}\text { Latihan } \\
\text { koordinasi } \\
\text { pretest }\end{array}$ & 0,161 & Normal \\
\hline 4 & Latihan & 0,139 & Normal \\
\hline
\end{tabular}




\begin{tabular}{|l|l|l|l|}
\hline & $\begin{array}{l}\text { koordinasi } \\
\text { posttest }\end{array}$ & & \\
\hline
\end{tabular}

Dari table di atas harga Asymp. Sig. dari variabel semuanya lebih besar dari 0,05 maka data variabel dalam penelitian ini dapat di analisis menggunakan statistik parametrik.

Dalam uji Homogenitas ini akan menguji hipotesis bahwa varians dari variabel-variabel tersebur sama, untuk menerima atau menolak hipotesis dengan membandingkan nilai Sig. lebih besar dari 0,05. Hasil uji homogenitas dapat dilihat pada tabel 4 di bawah ini:

Table 6. Hasil Perhitungan Uji Homogenitas

\begin{tabular}{|c|l|c|c|}
\hline No & Variabel & Sig. & Kesimpulan \\
\hline 1 & $\begin{array}{l}\text { Latihan } \\
\text { Konsentrasi }\end{array}$ & 0,254 & Homogen \\
\hline 2 & $\begin{array}{l}\text { Latihan } \\
\text { Koordinasi }\end{array}$ & 0,878 & Homogen \\
\hline
\end{tabular}

Dari hitungan diperoleh Sig. > 0,05, berarti varian sampel tersebut dikatakan homogen, maka hipotesis yang menyatakan varians subjek penelitian tersebut homogen.

Pengujian hipotesis ini menggunakan analisis statistik Paired Sample t-Test. Analisis data yang digunakan untuk menjawab hipotesis yang diajukan yaitu perbandingan antara latihan konsentrasi dan latihan koordinasi terhadap peningkatan kemampuan shooting game.

Untuk mengetahui ada atau tidak adanya perbedaan pengaruh latihan terhadap peningkatan kemampuan shooitng game. Pengujian hipotesis menggunakan Paired Sample t-Test tersaji pada tabel 7 sebagai berikut:

Tabel 7. Hasil Uji t Test Data Latihan Konsentrasi dan Latihan Koordinasi

\begin{tabular}{|c|c|c|l|l|}
\hline Variabel & Pretest & Posttest & Sig. & Kesimpulan \\
\hline $\begin{array}{c}\text { Latihan } \\
\text { Konsentrasi }\end{array}$ & 04,28 & 12,71 & 0,008 & Signifikan \\
\hline $\begin{array}{c}\text { Latihan } \\
\text { Koordnasi }\end{array}$ & 03,85 & 10,28 & 0,003 & Signifikan \\
\hline
\end{tabular}

Berdasarkan tabel 7, hasil analisis statistik

Paired Sample t-Test dari kelompok latihan konsentrasi maupun latihan koordinasi memiliki nilai $\mathrm{p}<0,05$ sehingga dapat diartikan bahwa baik latihan konsentrasi maupun latihan koordinasi dapat meningkat, namun berdasarkan hasil perhitungan SPSS, nilai rata-rata latihan konsentrasi yang mulanya 04,71 meningkat menjadi 13,00, jumlah peingkatannya sebesar 08,43 , dan latihan koordinasi yang mulanya 03,85 meningkat menjadi 10,28, jumlah peningkatannya sebesar 06,57. Dapat disimpulkan bahwa latihan konsentrasi hasilnya lebih baik meningkatkan kemampuan shooting daripada latihan koordinasi.

Penelitian ini bertujuan untuk mengetahui perbandingan antara latihan konsentrasi dan latihan koordinasi terhadap peningkatan kemampuan shooting game. Berdasarkan hasil penelitian menunjukkan terdapat pengaruh yang signifikan dari latihan konsentrasi dan latihan koordinasi terhadap peningkatan kemampuan shooting game. Perbandingan latihan konsentrasi dan tanpa latihan koordinasi terdapat perbedaan dari hasil uji-t dengan nilai rata-rata model latihan konsentrasi yang mulanya 04,71 meningkat menjadi 13,00, jumlah peningkatannya sebesar 08,28, dan latihan koordinasi yang mulanya 03,85 meningkat menjadi 10,00 , jumlah peneingkatan sebesar 06,57, menunjukkan bahwa latihan konsentrasi memberukan hasil yang lebih baik dibandingkan latihan koordinasi, dengan selisih nilai rata-tata 1,71 . Peningkatan kemampuan shooting atlet petanque Undikma dengan cara menggunakan latihan konsentrasi hasilnya lebih baik dibandingkat latihan koordinasi.

\section{KESIMPULAN}

Berdasarkan hasil penelitian yang telah diperoleh, maka dapat ditarik kesimpulan bahwa: Pertama, terdapat pengaruh latihan konsentrasi terhadap peningkatan kemampuan shooting game atlet petanque Undikma dengan nilai rata-rata pretest sebesar 4,7143 meningkat menjadi 13,000. Kedua, terdapat pengaruh latihan koordinasi terhadap peningkatan kemampuan shooting game atlet petanque Undikma dengan nilai rata-rata pretest sebesar 3,4286 meningkat menjadi 10,0000. Ketiga, terdapat perbedaan pengaruh latihan konsentrasi dan latihan koordinasi terhadap peningkatakan kemampuan shooting game atlet petanque Undikma. 


\section{SARAN}

Berdasarkan hasil penelitian yang disimpulkan di atas, peneliti menyampaikan beberapa saran: Pertama, peneliti selanjutnya harus membagi empat kelompok eksperimen denga empat perlakuan. Kedua, peneliti selanjutnya agar mengembangkan model-model latihan mental dan model latihan koordinasi pada program latihan petanque. Ketiga, latihan mental dan fisik disamping latihan teknik seharusnya diberikan simulasi atau ditekankan lagi sihingga mendapat hasil yang baik.

\section{UCAPAN TERIMA KASIH}

Ucapan terimakasih penulis sampaikan kepada Wakil Rektor II Undikma sekaligus sebagai pembina petanque Undikma.

\section{DAFTAR PUSTAKA}

Cox, R. H. (2011). Sport Psychology Concept and Applications. Mc Graw Hill.

Curran, K. (2018). The Effect of Salient and Neutral Distractors on Hand-Eye Coordination during Goal-Directed Reaching. University of Waterloo.

Firmansyah, H. (2011). Perbedaan Pengaruh Latihan Imagery dan Tanpa Latihan Imagery Terhadap Keterampilan Senam dan Kepercayaan Diri Atlet. Jurnal Olahraga Prestasi. Vol 7 pp 110.

Gilles Souef. (2015). The Winning Trajectory. Copymedia.

Irmansyah, J., Lubis, M. R., \& Permadi, A. G. (2018). Model Latihan imagery terhadap ketepatan floating service atlet voli pantai NTB. Jurnal Ilmiah Mandala Education, 4(2), 100.

Karageorghis, C., \& Terry, P. (2010) Inside sport psychology. Human Kinetics.

Komarudin. (2015). Psikologi Olahraga Latihan Keterampilan Mental Olahraga Kompetitif. Bandung : PT. Remaja Rosdakarya.

Lengkana, A.S., Tangkudung, J., \& Asmawi, M. (2018). The Effect of Power Limbs, Speed Reaction, Flexibility and Self Confidence on the Achievement of Elite Athletes Athletic West Java in the Track Number. Jipes-Journal of
Indonesia Physical Education and Sport, 4(2), 20-25.

Loehr, James. (1986). Mental Toughness Training for Sport. Achieving Athletic Excellence. Lexington, Massachusetts: The Stephen Greene Press.

Lubis, M., R. (2019). Perbedaan Latihan Shooting Menggunakan Penghalang dan Tanpa Penghalang Terhadap Peningkatan Kemampuan Shooting Game Atlet Pemula Petanque IKIP Mataram. In Proceeding National Conference: Education, Sosial Science, and Humaniora (Vol. 1, No. 1, pp. 287-300).

Putman B. W. (2011). PETANQUE The Gretatest Game You Never Heard Of!

Sugiyono. (2007). Statistik Untuk Penelitian. Bandung. Alfabeta

Suharsimi Arikunto. (2006). Prosedur Penelitian Suatu Pendekatan Praktik. Jakarta: PT. Rineka Cipta. 